\title{
Job Burnout, Job Satisfaction, and Related Factors among Health Care Workers in Golestan Province, Iran
}

\author{
Mohammad Javad Kabir ${ }^{1}$, Alireza Heidari ${ }^{2}$, Koorosh Etemad ${ }^{3}$, Ashrafi Babazadeh Gashti ${ }^{4}$, Nahid Jafari ${ }^{5}$, \\ Mohammad Reza Honarvar ${ }^{6}$, Mohammad Ariaee ${ }^{7}$, Mansureh Lotfi ${ }^{8}$
}

\begin{abstract}
${ }^{1}$ Ph.D. of Health Services Management, Assistant Professor, Health Management and Social Development Research Center, Golestan University of Medical Sciences, Gorgan, Iran

${ }^{2}$ Ph.D. Candidate in Health Policy, Department of Management and Health Economic, School of Public Health, Tehran University of Medical Sciences, Tehran, Iran

${ }^{3}$ Ph.D. of Epidemiology, Assistant Professor, Department of Epidemiology, Faculty of Public Health, Shahid Beheshti University of Medical Sciences, Tehran, Iran

${ }^{4}$ M.Sc., Medical Education, Health Management and Social Development Research Center, Golestan University of Medical sciences, Gorgan, Iran

${ }^{5} \mathrm{Ph} . \mathrm{D}$. of Community Health, Assistant Professor, Health Management and Social Development Research Center, Golestan University of Medical Sciences, Gorgan, Iran

${ }^{6} \mathrm{Ph} . \mathrm{D}$. Candidate in Nutrition Science, Health Management and Social Development Research Center, Golestan University of Medical Sciences, Gorgan, Iran

${ }^{7}$ M.Sc., Epidemiology, Deputy of Research, Golestan University of Medical Science, Gorgan, Iran

${ }^{8}$ M.Sc., Health services Management, Office of knowledge translation and research utilization, Vice-Chancellery for Research, Tehran University of Medical Sciences, Tehran, Iran
\end{abstract}

Type of article: Original

\begin{abstract}
Introduction: Burnout causes physical and emotional tireness, job dissatisfaction, resulting in reduced efficiency and a feeling of alienation from colleagues. Also, job satisfaction has a major impact on job-related behaviors, such as turnover intention, absenteeism, and job performance. The aim of this study was to determine job burnout, job satisfaction rate, and related factors among health care workers in Golestan Province in Iran.

Methods: This cross-sectional study was conducted with 1,141 health workers in Golestan Province in northern Iran. Data were collected using a questionnaire that was comprised of four sections. It consisted of socioeconomic characteristics, physical environment and facilities of health house (rural health clinic), Maslach burnout inventory, and a satisfaction questionnaire. Multi-nomial Logistic Regression was conducted to analyze the data using SPSS software, version 22.

Results: There were significant relationships between the intensity of job burnout and age $(p<0.001)$, years of experience $(p<0.001)$, low education level $(p=0.027)$, number of children $(p=0.002)$, dissatisfaction with income $(\mathrm{p}<0.001)$, physical environment of health houses $(\mathrm{p}=0.003)$, facilities of health houses $(\mathrm{p}=$ 0.025).There were significant relationships between the frequency of job burnout and age $(p<0.001)$, years of experience $(p<0.001)$, low education level $(p=0.016)$, number of children $(p=0.003)$, dissatisfaction with income $(p<0.001)$, and the physical environment of health houses $(p=0.008)$. There were significant relationships between job satisfaction and the satisfaction from income $(p=0.001)$, the physical environment of health houses $(\mathrm{p}=0.001)$, and the facilities of health houses $(\mathrm{p}=0.001)$.

Conclusion: Burnout was average among health workers, and health workers job satisfaction rate was lower than the average level in health workers. Effective interventions are recommended with regards to the unfavorable condition of job satisfaction and its relationship with job burnout.

Keywords: Job Burnout, Job Satisfaction, Health Care Workers, Golestan Province, Iran

\section{Corresponding author:}

Alireza Heidari, Department of Management and Health Economic, School of Public Health, Tehran University of Medical Sciences, Tehran, Iran. Tel: +98.9112780872, Fax:+98.2181633842, Email: alirezaheidari7@gmail.com Received: March 02, 2016, Accepted: May 17, 2016, Published: September 2016 iThenticate screening: May 16, 2016, English editing: July 04, 2016, Quality control: August 02, 2016

(c) 2016 The Authors. This is an open access article under the terms of the Creative Commons Attribution-NonCommercialNoDerivs License, which permits use and distribution in any medium, provided the original work is properly cited, the use is non-commercial and no modifications or adaptations are made.
\end{abstract}




\section{Introduction}

The concept of burnout is described as a response to the imbalance between the demands of work and personal resources (1). A high level of job stress, heavy volume of work, lack of social support, and role ambiguity are involved significantly in the onset of burnout syndrome (3), and it is related to negative attitudes toward patients and retire from work, absenteeism and job rotation (4-9). A person who is suffering from burnout often feels both physically and emotionally tired, unhappy with the job, has reduced efficiency, and feels alienated from colleagues (10). Job dissatisfaction is related to various behaviors, such as absenteeism, turnover intention, and job rotation (11 13). Job satisfaction has a major impact on job-related behaviors, such as turnover intention, absenteeism, and job performance (14). Dissatisfied health workers are more likely to have medical problems (15), and it is essential that they be healthy to ensure the stability of the health care providers' workforce (16). High job satisfaction of health workers leads to higher satisfaction among patients and lower costs for medical patients (17). In Iran, a health care worker who provides health services in rural areas is called behvarz. They work in rural health clinics called "Health Houses." The most important services they provide are in the following areas: 1) community education about health issues, 2) family health, 3) prenatal care, childbirth, and postpartum care, 4) care of children whose ages are less than five, 5) care of school-age children, 6) family planning services, 7) immunization, 8) home visits for follow-up, 9) case-finding and referral, 10) environmental health activities, and 11) information collection and records (18,19). If we pay more attention to the quality of the health care workforce, it will strengthen their competencies, optimize team communication, and strengthen the health workers' communication with local communities (20, 21). The aim of this study was to determine job burnout, job satisfaction rate, and related factors among health care workers in Golestan Province in Iran.

\section{Material and Methods}

\subsection{Study design and setting}

A cross-sectional study was conducted in 2012 in Golestan Province in northern Iran. Health workers working in health houses in the cities of of the Province, i.e., Gorgan, Ali Abad Katool, Azad Shahr, Gonbad-e Kavus, Ramian, Kalaleh, Galikesh, Gomishan, Bandar Torkaman, Bandar Gaz, Kordkoy, Maravetappe, Minoodasht, and Agh Ghala, participated in this study. There were 1,275 health workers who participated in this study, and 1,141 of them agreed to complete the questionnaire (a response rate of $89 \%$ ).

\subsection{Instrument}

Data were collected using a questionnaire that consisted of four sections. The first section dealt with the socioeconomic characteristics of the participants (gender, age, work experience, educational level, marital status, spouse's education, number of children, ethnicity, population coverage, housing, spouse's job, second job, the possibilities of life, and satisfaction with income). The second section addressed the physical environment and facilities of the health house, e.g., the light, noise, air conditioning, paint on the walls, heating, cooling, fitness between sevices and space, and the appearance of the building. The facilities included stationery, medical equipment, drugs, office equipment (e.g., tables, chairs, benches, shelves, and files), and a telephone. This section was developed in 14 questins and categorized as "Strongly agree", "Agree", "Null", "Disagree", and "Strongly disagree." The answers were scored from 5 to 1 for "Strongly agree" to "Strongly disagree," respectively. In order to categorize, the range of the highest and the lowest score was divided into three levels, i.e., below $40 \%$ of the maximal score was poor, $40-$ $60 \%$ of the maximal score was intermediate, and $61-100 \%$ of the maximal score was good. In this section, the validity of the questionnaire was confirmed by the experts of the subject, and its reliability was acceptable with a Cronbach's alpha of 0.84 . The first and second sections were developed based on comments of an expert group that consisted of health managers and faculty members. In the third section, the Maslach burnout inventory was used, and the questions dealt with emotional exhaustion (nine items), depersonalization (eight items), and personal performance (four items). Each item also was rated on frequency and intensity scales. The frequency scale consisted of a 7-pont rating scale $(0=$ never; $1=$ a few times a year; $2=$ monthly; $3=$ a few times a month; $4=$ every week; 5 $=\mathrm{a}$ few times a week; 6 = every day). Also, the intensity scale consisted of a 7 -point rating scale $(0=$ never; $1=$ very mild; 2 = barely noticeable; 3 = moderate; 4 = strong; 5 = very strong; $6=$ major). The validity of the questionnaire was confirmed by experts, and its reliability was acceptable with a Cronbach's alpha of 0.95 . In the fourth section, The Herzberg job satisfaction questionnaire was used, and the questions dealt with nine domains, i.e., organizational communications, career advancement, salary, social acceptability, staff maintenance and support factors, management, job with challenges, pay attention to the potential ability, and experience in giving people responsibility. Answers were classified as very low, low, medium, high, and very high. In questions with a positive meaning, the answers were scored from 5 to 1 for "very high" to "very low", respectively, and the inverse was true 
for questions with a negative meaning. The validity of the questionnaire was confirmed by experts, and its reliability was acceptable with a Cronbach's alpha of 0.90. Table 1 indicates the features of the questionnaire.

Table 1. Features of the Questionnaire

\begin{tabular}{|c|c|c|}
\hline Section & Source & Items \\
\hline $\begin{array}{l}\text { Socio-economic } \\
\text { characteristics }\end{array}$ & Expert group & $\begin{array}{l}\text { Gender, age, work experience, educational level, marital status, } \\
\text { spouse's education, number of children, ethnicity, population } \\
\text { coverage, housing, spouse's job, second job, satisfaction with } \\
\text { income. }\end{array}$ \\
\hline $\begin{array}{l}\text { Physical environment } \\
\text { and facilities of } \\
\text { health house }\end{array}$ & Expert group & $\begin{array}{l}\text { Light, noise, air conditioning, painting the walls, the heating, } \\
\text { cooling, the fitness between services and space and the appearance } \\
\text { of the building. Stationaries, medical equipment, drugs, office } \\
\text { equipment (e.g., tables, chairs, benches, shelves, files) and } \\
\text { telephone. }\end{array}$ \\
\hline Burnout & $\begin{array}{l}\text { Maslach burnout } \\
\text { inventory }\end{array}$ & Emotional exhaustion, depersonalization, personal performance. \\
\hline Job satisfaction & $\begin{array}{l}\text { Herzberg job } \\
\text { satisfaction } \\
\text { questionnaire }\end{array}$ & $\begin{array}{l}\text { Organizational communications, career advancement, salary, social } \\
\text { acceptability, staff maintenance and support factors, management, } \\
\text { job with challenges, pay attention to the potential ability, experience } \\
\text { in giving people responsibility. }\end{array}$ \\
\hline
\end{tabular}

\subsection{Data collection}

After approval of the research project, representatives of Province's health workers were invited to a meeting. In the meeting, we explained the study's objectives, the content of the questionnaire, and ethical considerations in data collection. Questionnaires were distributed and managed by trained representatives. The self-administered questionnaires were completed and returned by the health workers.

\subsection{Research ethics}

The project was approved by the Ethics Committee of Golestan University of Medical Sciences (9104130132). The principles of ethics in the study were approved. In this way, the participants were informed about the objectives of the study and their verbal consent to participate was obtained. The health workers participated in the study voluntarily, and the questionnaires were distributed anonymously among them.

\subsection{Statistical analysis}

Descriptive statistics were presented via mean \pm SD and percentages. Data were analyzed using Multinomial Logistic Regression on IBMC SPSS C Statistics, version 22 (IBM@ Corp., Armonk, NY, USA).

\section{Results}

The mean age of the participants was $37.28 \pm 6.8$, and the mean work experience was $17.25 \pm 6.7$. Most respondents were women (63.1\%) and married (93.5\%), had diploma degree (68.8\%), had two children (39.6\%), their spouse's job was often employee (30.8\%), their spouse's education was diploma (32.5\%), Turkmen ethnicity (44.2\%), lived in the village $(72.1 \%)$, and house owner (69\%). Nearly $6 \%$ had a second job, and $26.5 \%$ of them were dissatisfied with their income. Overall, $48.8 \%$ of the health care workers reported that the physical environment of their health houses was good, $33.7 \%$ reported that it was moderate, and $17.5 \%$ reported that it was poor. In total, 39.1, 36.1, and $24.8 \%$ of subjects reported that facilities of health houses were good, moderate, and poor, respectively. The frequencies of job burnout among the participants were low, moderate, and high in 47.2, 44.2, and 8.6\% of the participants. The intensity of job burnout of participants was low, average, and high in 46.5, 44.4, and 9.1\%, respectively. There were significant relationships between the intensity of job burnout and age $(\mathrm{p}<0.001)$, years of experience $(p<0.001)$, low educational level $(p=0.027)$, number of children $(p=0.002)$, dissatisfaction with income $(p<0.001)$, physical environment of health houses $(p=0.003)$, and the facilities of the health houses $(p=$ 0.025). There were no significant relationships between the intensity of job burnout and gender $(p=0.842)$, marital status $(p=0.382)$, spouse's job $(p=0.882)$, spouse's educational level $(p=0.218)$, ethnicity $(p=0.611)$, housing $(p$ $=0.233)$, having a second job $(\mathrm{p}=0.503)$, and underserved population $(\mathrm{p}=0.946)$. There were significant relationships between the frequency of job burnout and age $(\mathrm{p}<0.001)$, years of experience $(\mathrm{p}<0.001)$, low educational level $(p=0.016)$, number of children $(p=0.003)$, dissatisfaction with income $(p<0.001)$, and the physical environment of health houses $(\mathrm{p}=0.008)$. There were significant relationships between the frequency of 
job burnout and gender $(p=0.49)$, marital status $(p=0.24)$, spouse's job $(p=0.571)$, spouse's educational level $(p=$ $0.215)$, ethnicity $(p=0.750)$, housing $(p=0.233)$, having a second job $(p=0.914)$, facilities of the health houses $(p$ $=0.421)$, and underserved population $(\mathrm{p}=0.993)$. The mean of the job satisfaction score was $2.41 \pm 0.62$, which indicated a relatively dissatisfied level. The mean of scores for dimensions of organizational communications, career advancement, salary, social acceptability, staff maintenance and support factors, management, job with challenges, pay attention to the potential ability, and experience in giving people responsibility were $2.4 \pm 0.83$ (relatively dissatisfied), $2.02 \pm 0.79$ (relatively dissatisfied), $2.05 \pm 0.72$ (relatively dissatisfied), $3.01 \pm 0.8$ (relatively dissatisfied), $1.93 \pm 0.85$ (dissatisfied), $2.42 \pm 0.89$ (relatively dissatisfied), $2.49 \pm 0.61$ (relatively dissatisfied) and $1.99 \pm 0.78$ (dissatisfied). There were significant statistical relationships between job satisfaction and the satisfaction from income $(p=0.001)$, physical environment of the health houses $(p=0.001)$, and the facilities of the health houses $(p=0.001)$. There were not significant statistical relationships between job satisfaction and age $(p=0.556)$, work experience $(\mathrm{p}=0.536)$, gender $(\mathrm{p}=0.560)$, health worker's educational level $(\mathrm{p}=0.536)$, marital status $(\mathrm{p}=$ $0.171)$, ethnicity $(p=0.282)$, spouse's job $(p=0.712)$, spouse's educational level $(p=0.234)$, housing $(p=0.242)$, number of children $(p=0.282)$, having a second job $(p=0.371)$ and underserved population $(p=0.249)$. Table 2 indicates some factors that are related to job burnout and job satisfaction. There was a significant relationship between job burnout and job satisfaction $(p=0.001)$.

Table 2. Factors related to job burnout and job satisfaction among health care workers

\begin{tabular}{|l|l|l|l|}
\hline \multirow{2}{*}{ Variable } & p-value & \multicolumn{2}{l|}{} \\
\cline { 2 - 4 } & Frequency of job burnout & Intensity of job burnout & Job satisfaction \\
\hline Age & $<0.001$ & $<0.001$ & 0.556 \\
\hline Work experience & $<0.001$ & $<0.001$ & 0.536 \\
\hline Gender & 0.49 & 0.842 & 0.560 \\
\hline Education level & 0.032 & 0.027 & 0.536 \\
\hline Marital status & 0.24 & 0.382 & 0.171 \\
\hline Spouse's education & 0.215 & 0.218 & 0.234 \\
\hline Spouse's job & 0.571 & 0.882 & 0.712 \\
\hline Number of children & 0.003 & 0.002 & 0.242 \\
\hline Ethnicity & 0.750 & 0.611 & 0.282 \\
\hline Housing & 0.233 & 0.233 & 0.242 \\
\hline Second job & 0.914 & 0.503 & 0.371 \\
\hline Satisfaction with income & $<0.001$ & $<0.001$ & 0.001 \\
\hline Physical environment of health houses & 0.008 & 0.001 & 0.001 \\
\hline facilities of health houses & 0.421 & 0.003 & 0.001 \\
\hline Underserved population & 0.946 & 0.993 & 0.249 \\
\hline
\end{tabular}

\section{Discussion}

Burnout was average among health workers, which was inconsistent with Gordon's (22) and Sobral et al.'s (23) studies; however, in contrast to the current study; burnout was at a weak level in Nicola's (24) and Mirabzadeh's (25) studies and at a high level in Aziznejad's (26) and Sfandyari's (27) studies. These differences could be due to differences in the demographic characteristics, the nature of the work, and the study environment. The job satisfaction rate was lower than the average level in the majority of health workers, which was in line with Kumar et al.'s (28) and Cohen and Sarter's (29) studies; however, it was not in agreement with Bodur and colleagues' (30) and Carrillo-Garcia's (31) studies. These differences may be likely due to differences in the research areas and time to gather information that could affect the job burnout and job satisfaction. Older and more experienced health workers suffered from burnout more than others. It seems that the health workers who were more involved with the problems of life and activities in the health house had greater complexity than in the past. Although it seems that experience in dealing with the problems may reduce job burnout, but the results did not confirm this issue. This could have been by the fact that they were not able to adapt to their working conditions. More experienced health workers were satisfied to a greater extent than others, which was similar to Khamlub and colleagues' study (32), while, it was not similar to the findings of Zontek and colleagues' (33) studies. It seems, if a health worker were satisfied with her job, job satisfaction increased with increasing experience; but, if she were not satisfied, age and experience do not have a significant impact on job satisfaction. Higher levels of burnout were associated with workers who had lower educational levels. The level of educational had an important role in improving the social aspect. The health workers can be likely more inclined to severe job burnout if they could not enhance their 
education or if they did so but their job remained the same. Health workers who had more children suffered from more job burnout. In the culture of a rural community, the average age of marriage is lower than in cities. Therefore, the health workers who marry earlier probably have more children. As the number of children increases, the workers' living expenses and stress increase, which contributes to burnout. Dissatisfaction with income increased job burnout. It seems that problems of living and the disparity between salaries and the level of inflation can cause burnout in health workers. Job satisfaction was different in numerous studies. This was similar to Tran and colleagues' study (34). These differences can be the result of management style, organizational culture in different cities, and people's cooperation in improving the health of the village. Job satisfaction was different among ethnic groups. This could be due to values, ethics, and beliefs of the working life of the various ethnic groups. The aforementioned issues can affect health workers' feelings toward their work. The health workers who had more job satisfaction had lower job burnout. This is similar to with Rosales and colleagues' study (35) and Sarmiento et al.'s (36) study. Some of the limitations of this study included the poor collaboration of health workers in responding to the questionnaire. Hence, we made arrangements with health authorities and obtained the required permission. Another limitation was their concern that their answers may be provided to their managers. For this problem, we explained the aim of the study to the participants and reassured them about the anonymity of their information. Given that the study was conducted in one province, it should be done with a larger size.

\section{Conclusions}

The results showed that burnout was average among health workers and that their job satisfaction rate was lower than the average level. Therefore, our research can help to improve the work environment, which should contribute to providing better services. Psychologists of counseling centers can help to improve the working relationships of health workers with other staff members and teach adaptive methods and mechanisms of adaptation. It is necessary to provide promotions, higher positions, and enhancements in these fields. With further studies, we can determine the causes of job dissatisfaction in qualitative studies. Also, it would be beneficial to conduct interventional studies to determine the best interventions to increase the job dissatisfaction of health workers.

\section{Acknowledgments:}

This research was supported financially by the Deputy of Research and Technology of Golestan University of Medical Sciences with grant number 9104130132 . The authors appreciate the contributions that were made by the health care workers of Golestan Province.

\section{Conflict of Interest:}

There is no conflict of interest to be declared.

\section{Authors' contributions:}

All authors contributed to this project and article equally. All authors read and approved the final manuscript.

\section{References:}

1) Maslach C, Schaufeli WB, Leiter MP. Job burnout. Annu Rev Psychol. 2001; 52: 397-422. doi: 10.1146/annurev.psych.52.1.397. PMID: 11148311.

2) Schaufeli WB, Maslach C, Marek T. Professional Burnout: Recent Developments in Theory and Research. Taylor \& Francis, Washington, DC. 1993.

3) Vahey DC, Aiken LH, Sloane DM, Clarke SP, Vargas D. Nurse burnout and patient satisfaction. Med Care. 2004; 42(2): 57-66. doi: 10.1097/01.mlr.0000109126.50398.5a. PMCID: PMC2904602.

4) Poghosyan L, Clarke SP, Finlayson M, Aiken LH. Nurse burnout and quality of care: cross-national investigation in six countries. Res Nurs Health. 2010; 33(4): 288-98. doi: 10.1002/nur.20383. PMID: 20645421, PMCID: PMC2908908.

5) Leiter MP, Harvie P, Frizzell C. The correspondence of patient satisfaction and nurse burnout. Soc Sci Med. 1998; 47(10): 1611-7. PMID: 9823056.

6) Cordes CL, Dougherty TW. A review and integration of research on job burnout. Acad Manage Rev. 1993; 18: 621-56. doi: 10.5465/AMR.1993.9402210153.

7) Turan JM, Bukusi EA, Cohen CR, Sande J, Miller S. Affects of HIV/AIDS on Maternity Care Providers in Kenya. J Obstet Gynecol Neonatal Nurs. 2008; 37(5): 588-95. doi: 10.1111/j.1552-6909.2008.00281.x. PMID: 18811779, PMCID: PMC2556865. 
8) Kruse GR, Chapula BT, Ikeda S, Nkhoma M, Quiterio N, Pankratz D, et al. Burnout and use of HIV services among health care workers in Lusaka District. Zambia: a cross-sectional study. Hum Resour Health. 2009; 7: 55. doi: 10.1186/1478-4491-7-55, PMCID: PMC2714832.

9) Ashtari Z, Farhady Y, Khodaee MR. Relationship between job burnout and work performance in a sample of Iranian mental health staff. Afr J Psychiatry. 2009; 12(1): 71-4. PMID: 19526650.

10) Melo MB, Barbosa MA, Souza PR. Job satisfaction of nursing staff: integrative review. Rev Lat Am Enfermagem. 2011; 19(4): 1047-55. PMID: 21876960.

11) Tzeng HM. The influence of nurses' working motivation and job satisfaction on intention to quit: an empirical investigation in Taiwan. Int J Nurs Stud. 2002; 39: 867-78. PMID: 12379304.

12) Coomber B, Barriball KL. Impact of job satisfaction components on intent to leave and turnover for hospital-based nurses: a review of the research literature. Int J Nurs Stud. 2007; 44(2): 297-314. PMID: 16631760.

13) Hayes LJ, O'Brien-Pallas L, Duffield C, Shamian J, Buchan J, Hughes F, et al. Nurse turnover: a literature review. Int J Nurs Stud. 2012; 49(7): 887-905. doi: 10.1016/j.ijnurstu. 2011.10.001. PMID: 22019402.

14) Faragher EB, Cass M, Cooper CL. The relationship between job satisfaction and health: a meta-analysis. Occup Environ Med. 2005; 62: 105-12. doi: 10.1136/oem.2002.006734.

15) Sundquist J, Johannsson SE: High demand, low control, and impaired general health: working conditions in a sample of Swedish general practitioners. Scand J Public Health. 2000, 28(2): 123-31. PMID: 10954139.

16) Fahrenkopf AM, Sectish TC, Barger LK, Sharek PJ, Lewin D, Chiang VW, et al. Rates of medication errors among depressed and burnt out residents: prospective cohort study. BMJ. 2008; 336(7642): 488-91. doi: 10.1136/bmj.39469.763218.BE. PMID: 18258931, PMCID: PMC2258399.

17) John O. Smart thinking for challenged health systems. Mark Health Serv. 2002; 22(2): 24-8.

18) Malakouti SK, Nojomi M, Salehi M, Bijari B. Job Stress and Burnout Syndrome in a Sample of Rural Health Workers, Behvarzes, in Tehran, Iran. Iran J Psychiatry. 2011; 6(2): 70-4. PMID: 22952525, PMCID: PMC3395939.

19) Shadpour K. The PHC experience in Iran. Teheran: United Nations Children's Fund; 1994.

20) Abhari M. A report of mental health services and integration of mental health in Primary Health Care system in Savojbolagh. Iran J Psychiatry Clin Psychol. 1998; 4: 29-39.

21) Bonenberger M, Aikins M, Akweongo P, Wyss K. The effects of health worker motivation and job satisfaction on turnover intention in Ghana: a cross-sectional study. Hum Resour Health. 2014; 12: 43. doi: 10.1186/1478-4491-12-43. PMID: 25106497, PMCID: PMC4130118.

22) Buykx P, Humphreys J, Wakerman J, Pashen D. Systematic review of effective retention incentives for health workers in rural and remote areas: towards evidence-based policy. Aust J Rural Health. 2010; 18(3): 102-9. doi: 10.1111/j.1440-1584.2010.01139.x.

23) Da Silva Sobral De Matos H, Daniel Vega E, Perez Urdaniz A. A study of the burnout syndrome in medical personnel of a general hospital. Actas ESP Psiquiatr. 1999; 27(5): 310-20. PMID: 10545662.

24) Payne N. Occupational stressors and coping as determinants of burnout in female hospice nurses. J Adv Nurs. 2001; 33(3): 396-405. PMID: 11251727.

25) Mirabzadeh A, Irani S, Samiei M, Feizzadeh G. Burnout and It's Effective Factors Among the Personnel of Razi Psychiatric Hospital. J Rehab. 2007; 8(2): 64-70.

26) Aziz Nejad P, Hosseini SJ. Occupational burnout and its causes among practicing nurses in hospitals affiliated to Babol University of Medical Sciences, 2004. JBUMS. 2006; 8(2): 63-9.

27) Esfandiari GR. Survey of the rate of occupational burnout between nursing staff of Sanandaj hospitals affiliated to Kurdistan University of Medical Sciences in 2001. Scientific Journal Of Kurdistan Unniversity Of Medical Sciences. 2001; 6(1): 31-5.

28) Kumar P, Khan AM, Inder D, Mehra A. A comparative study of job satisfaction among regular and staff on contract in the primary health care system in Delhi, India. J Family Community Med. 2014; 21(2): $112-18$. doi: 10.4103/2230-8229.134768. PMID: 24987280, PMCID: PMC4073559.

29) Cohen MZ, Sarter B. Love and work: oncology nurses' view of the meaning of their work. Oncol Nurs Forum. 1992; 19(10): 1481-6. PMID: 1461762.

30) Bodur S. Job satisfaction of health care staff employed at health centres in Turkey. Occup Med. 2002; 52(6): 353-5. PMID: 12361997.

31) Carrillo-Garcia C, Solano-Ruiz Mdel C, Martinez-Roche ME, Gomez-Garcia CI. Job satisfaction among health care workers: the role of gender and age. Rev Lat Am Enfermagem. 2013; 21(6): 1314-20. 
32) Khamlub S, Harun-Or-Rashid M, Sarker MA, Hirosawa T, Outavong P, Sakamoto J. Job satisfaction of health-care workers at health centers in Vientiane Capital and Bolikhamsai Province, Lao PDR. Nagoya J Med Sci. 2013; 75(3-4): 233-41. PMID: 24640179.

33) Zontek TL, DuVernois CC, Ogle BR. Job satisfaction and issues related to the retention of environmental health professionals in North Carolina. J Environ Health. 2009; 72(3): 10-5. PMID: 19882986.

34) Tran BX, Van Hoang M, Nguyen HD. Factors associated with job satisfaction among commune health workers: implications for human resource policies. Glob Health Action 2013; 6:1-6. doi: 10.3402/gha.v6i0.18619

35) Rosales RA, Labrague LJ, RosalesGL. Nurses' Job satisfaction and Burnout: Is there a connection? IJANS 2013; 2(1): 1-10. doi: 10.14419/ijans.v2i1.583.

36) Sarmiento TP, Laschinger HK, Iwasiw C. Nurse educators workplace empowerment, Burnout \& Job satisfaction, Testing Kanter's Theory. J Adv Nurs. 2004; 46(2): 134-43. PMID: 15056326. 